\title{
Accessibility to and utilisation of schistosomiasis-related health services in a rural area of state of Minas Gerais, Brazil
}

\author{
Dener Carlos dos Reis ${ }^{1,4}$, Helmut Kloos², Charles King ${ }^{3}$, Humberto Ferreira Oliveira Quites ${ }^{1,4}$, \\ Leonardo Ferreira Matoso ${ }^{1,4}$, Kellen Rosa Coelho ${ }^{1,4}$, Andrea Gazzinelli, ${ }^{1,4} /+$

\begin{abstract}
'Escola de Enfermagem, Universidade Federal de Minas Gerais, Belo Horizonte, MG, Brasil ${ }^{2}$ Department of Epidemiology and Biostatistics, University of California Medical Center, San Francisco, CA, USA ${ }^{3}$ Center for Global Health \& Diseases, Department of Epidemiology and Biostatistics, Case Western University, Cleveland, OH, USA ${ }^{4}$ Instituto Nacional de Ciência e Tecnologia em Doenças Tropicais, Brasil
\end{abstract}

The objective of the present paper was to compare accessibility and utilisation of schistosomiasis diagnostic and treatment services in a small village and the surrounding rural area in northern part of the state of Minas Gerais Brazil. The study included 1,228 individuals: 935 central village residents and 293 rural residents of São Pedro do Jequitinhonha. Schistosoma mansoni infection rates were significantly higher in the central village than in the rural area during a survey in 2007 (44.3\% and 23.5\%, respectively) and during the 2002 schistosomiasis case-finding campaign $(33.1 \%$ and $26.5 \%$, respectively) $(p<0.001)$. However, during the $2002-2006$ period, only $23.7 \%$ of the villagers and $27 \%$ of the rural residents obtained tests on their own from health centres, hospitals and private clinics in various nearby towns. In 2007, 63\% of the villagers and $70.5 \%$ of the rural residents reported never having received treatment for schistosomiasis. This paper reveals considerable variation in the accessibility and utilisation of schistosomiasis-related health services between the central village and the rural area. A combination of low utilisation rates between 2002-2006 and persistently high S. mansoni infection rates suggest that the schistosomiasis control program must be more rapidly incorporated into the primary health services.

Key words: schistosomiasis - access to health care - spatial - health-seeking behaviour

The limited accessibility of diagnostic, chemotherapeutic and preventive services significantly constrains the health-seeking behaviour of people infected with schistosomiasis and other infectious diseases, especially in developing countries. In addition, a lack of information, the costs of travel and health-services fees, geographic distance, social factors and frequently unavailable services are also major barriers people face in accessing health services (Gesler 1984, Almeida et al. 2000, da Silva et al. 2000, Andersen et al. 2002, Assis et al. 2003, Mendoza-Sassi et al. 2003, Barata et al. 2007). Illness perceptions, the use of traditional medicines, lack of knowledge about the treatment of diseases in modern facilities and personal preferences may also lead to a low demand for health services (Gesler 1984, Gazzinelli et al. 1998, Mendoza-Sassi et al. 2003).

While approaches to studying access to and utilisation of health care have evolved over the years, these two health services parameters may be defined as the capacity of a person or group to obtain effective care when needed in the desired form and in a convenient

Financial support: UNICEF/UNDP/World Bank/WHO/TDR, Fogarty International Centre Training Grant (1D43TW006580), FAPEMIG

+ Corresponding author: andreag@enf.ufmg.br

Received 29 December 2008

Accepted 16 October 2009 way (Kumar 2004, Travassos \& Martins 2004). A combination of poverty, underdeveloped health systems and geographical constraints impact both patients' abilities to access services and the ability of health facilities to provide adequate and effective services; these issues are even more acute in developing countries. Socioeconomic status (particularly income, occupation and level of education), ethnicity, age and gender inequities are major patient-related factors that impede access to health services (Gesler 1984, Almeida et al. 2000, Travassos \& Martins 2004, Barata et al. 2007). Illiteracy and a lack of social capital may further reduce the ability of poor populations to access care, particularly in the absence of available health services and information about the transmission, health impacts, proper treatment and prevention of disease (Hendryx et al. 2002, Lee et al. 2004). A lack of social capital may also limit cooperative activities and interactions among local health services and other government services (Watts 2008). Personal characteristics of individuals and groups, including clients' and health providers' attitudes towards each other, space-time opportunities and constraints in accessing services also affect accessibility and utilisation (Kumar 2004, Haile-Mariam \& Kloos 2006). Research indicates that the accessibility problem can only be solved if barriers surrounding both providers and users of services are reduced or eliminated (Travassos et al. 2000, Hendryx et al. 2002, Travassos \& Martins 2004, Gerhardt 2006).

Although many control programs have reduced the prevalence, intensity and transmission of schistosomiasis, especially in Latin America and most of the West Indies and the Middle East, these achievements have 
been offset by increasing infection rates in Sub-Saharan Africa, the result of population movements and other factors (Savioli et al. 2004). But even in countries that have made great progress in schistosomiasis control, including Brazil, new transmission foci are periodically being reported due to the creation of new transmission sites around water resources projects, population movements and lack of safe water supplies and sanitary facilities (Engels et al. 2002, Barbosa et al. 2004, Enk et al. 2004). While lower production costs and the expansion or decentralisation of health services have improved the distribution of praziquantel, the schistosomiasis drug of choice (Savioli et al. 2004), little is known about the problems faced by people who are coping with infection and trying to access health services. Information is most urgently needed in poor, geographically isolated areas where health services are weakest and economic, social, cultural and logistical barriers facing patients are usually most problematic.

Schistosomiasis remains an important health problem in Brazil. In Minas Gerais (MG) alone, which together with the state of Bahia was only included in the national program in 1990, an estimated 10 million of the 16 million inhabitants, mostly in the poorer northern part of the state, are at risk of infection. The control strategy of the national program has consisted mostly of chemotherapy and the use of molluscicides, although the use of molluscicides has greatly decreased in recent years due to the development of less environmentally toxic and more cost-effective and human-focused control strategies (Barbosa 1995, Coura 1995, MS 2008). Chemotherapy has been increasingly used to reduce the prevalence, intensity and clinical status of the disease. Safe water supplies, sanitary facilities and health education activities have been used less systematically, although they are potentially effective control measures (Katz 1998, WHO 2001). In the late 1990s, all control programs for endemic diseases, including schistosomiasis, were decentralised to the municipality level and administered through the strengthened primary care system; this strategy was designed to improve equitable access to diagnostic and treatment services in both rural and urban areas (MS 2005). However, the impact of decentralisation on schistosomiasis control has not been assessed and most endemic areas have not integrated these activities into primary health care.

The Schistosomiasis Control Program (SCP) gives priority to active case detection, although treatment campaigns, normally carried out every two years, cover only some of the endemic communities and are not fully systematised in most of the country's states and municipalities. For example, some hyper-endemic communities in northern MG have either not been included in the control program or have received irregular diagnostic and treatment services. We studied the epidemiology of schistosomiasis in six rural communities in northern MG where schistosomiasis prevalence rates were $50 \%$ or higher between the early 1990s and 2005 (Kloos et al. 1998, Bethony et al. 2001, Gazzinelli et al. 2006a). These and other communities with hyper-endemic schistosomiasis, including many in the states of Pernambuco
(PE) (Favre et al. 2001, Barbosa et al. 2006) and Alagoas (AL) (Coura \& Amaral 2004), represent remnants of the earlier high-transmission situation that prevailed throughout much of Brazil. While many areas of Brazil experience low transmission and morbidity rates today, recent increases in the prevalence of schistosomiasis in AL and the Federal District (Coura \& Amaral 2004) and the finding that only $8.4 \%$ of the 1.2 million people living in the rainforest zone of PE had been covered by the SCP within the Serviço Único de Saúde (SUS) by 2004 (Favre et al. 2006) are a cause for concern. The "staged control" approach recommended by the World Health Organization calls for a shift from a targeted approach emphasising morbidity control in high transmission areas to a community-wide approach focusing on transmission and infection control in areas of low transmission; however, the need to identify infected people and to facilitate their access to chemotherapy persists into the surveillance stage (WHO 2001).

All primary health services in Brazil began to be integrated into the public health system created at the end of the 1980s (SUS). This system is based on three essential principles: universality of access, integrated care and decentralisation to the municipality level. The current health policy of Brazil calls for the integration of the national SCP into the primary health services, with a focus on improving access to diagnostic services, treatment and health education. The Committee on Schistosomiasis and Soil-transmitted Helminthiases of the federal Brazilian Ministry of Health recently passed a resolution that called for better access to chemotherapy through primary health care services as part of the regular provision of treatment to high-risk groups and for the implementation of plans for basic sanitation and safe water supplies (FUNASA 1998, MS 2005). Nevertheless, although the public health system has brought health care to many poor people in recent decades (Jurberg 2008), health levels and access to care remain significantly lower in rural than in urban areas (Sastry 1997).

Although access to and utilisation of health services in Brazil and nearly all other countries are greater in urban than in rural areas, little is known about health behaviour within rural areas. In rural areas of the Ivory Coast, the poorest schoolchildren in 57 primary schools lived significantly farther away from public health services (Raso et al. 2005), and in Ghana, nearly half of the residents of a rural village either lacked money for a physician or did not consider the schistosomiasis-related symptoms important enough to visit the health services (Danso-Appiah et al. 2004). In Brazil, schistosomiasis risk has been associated with socioeconomic and demographic factors in different communities (Lima e Costa et al. 1998, Gazzinelli et al. 2006a, Guimarães et al. 2006, Silva et al. 2007) and distinct infection clusters have been identified in small rural communities (Gazzinelli et al. 2006b). However, no information is available on health-seeking behaviour in those areas. At the national level, gender differences in health reporting indicate that women's health is poorer than men's health (Barata et al. 2007), but no information is available on the self-reporting of schistosomiasis. The objective of the present 
paper was to compare access to and utilisation of schistosomiasis diagnostic and treatment services in a small village and the surrounding rural area in northern MG. Our results may provide new information on patterns and problems surrounding health-seeking behaviour related to the provision of schistosomiasis services in rural communities in Brazil.

\section{PATIENTS, MATERIALS AND METHODS}

The study area, economy and population - This study was carried out between October 2006-April 2008 in the municipality of São Pedro do Jequitinhonha in the northern part of MG, Brazil. The district of São Pedro, located along the north-eastern shore of the Jequitinhonha River, is approximately $40 \mathrm{~km}^{2}$. It consists of two settlements: a central village and the surrounding rural area. The economy of the area is based on subsistence farming (involving the cultivation of staple crops like maize and manioc) and cattle raising. The main sources of income include remittances for migrant laboures, small-scale sales of manioc and milk, pension payments and government financial support to poor families (Bolsa Família) earning less than $\mathrm{R} \$ 60,00$ (about US\$30.00) per capita per month. The central village includes one elementary/high school and a primary health centre. The study population of 1,228 people (according to the 2007 census) lives in the central village of São Pedro (245 households) and in the rural area (89 households). The prevalence of schistosomiasis in the study population was $39.4 \%$ in 2007 and was higher among central village residents $(44.8 \%)$ than rural residents $(24.8 \%)(\mathrm{p}<0.001)$ (Table I).

Local health services - The single municipality-operated primary health centre in São Pedro, located in the central village, has a part-time physician and nurse who attend three days a week and a full-time nurse auxiliary and health agent; there are no laboratory facilities. The rural population has relatively less access to the health centre because of the distance and the hilly terrain. To reach the nearest hospital and the pharmacies in the town of Jequitinhonha (40 km downstream from São Pedro), people must cross the Jequitinhonha River by ferry and then take a public bus. The only other primary health centre and pharmacies within a day's travel are located in the municipality of Itaobim, about $15 \mathrm{~km}$ upstream from São Pedro. The last case-finding campaign of the SCP in the study area, involving diagnosis and treatment of infected persons, was carried out in 2002.

Data collection - The household questionnaire was pre-tested and a considerable number of changes were necessary to administer it effectively. The interviews were carried out between May-July of 2007 by experienced nursing graduate students using Personal Digital Assistants (PDA). All households and individuals were given unique code numbers during an initial visit. Interviews were carried out in all houses in the study area using a questionnaire containing questions about previous schistosomiasis treatment, demographic and socioeconomic status and schistosomiasis-related diagnoses and treatment.
Household heads were interviewed about householdrelated matters and each individual over the age of 18 years was interviewed about his or her personal characteristics and health-seeking behaviours. Socioeconomic characteristics were recorded for each household and each individual was asked about demographic characteristics, perceptions of schistosomiasis as a disease, the use of home remedies, utilisation of diagnostic and treatment services for schistosomiasis, details of trips to health facilities, level of satisfaction with health services and previous treatment for schistosomiasis. Information on children under the age of 18 years was gathered from their parents.

Information was also gathered retrospectively on utilisation patterns for the 2002 schistosomiasis campaign since there are no patient records from that campaign. This campaign typically focuses on examining all persons living in the endemic areas and treating all Schistosoma mansoni cases. In 2002, health workers went from house to house to explain the program and distribute stool containers to all inhabitants. However, just one stool sample was examined using a Kato-Katz method (Katz et al. 1972). In addition, because of the difficulty in accessing many households, particularly in the rural section of the district, not everyone in the study area was covered by this campaign. Questions were included on the utilisation of schistosomiasis diagnostic and treatment services between 2002 and the end of 2006 to permit an estimate of utilisation rates during that period, when no schistosomiasis campaigns were carried out in the study area. The fact that people remembered the 2002 campaign and the characteristics of the schistosomiasis treatment (including a trip to the Department of Schistosomiasis Control in the town of Jequitinhonha) is thought to have reduced recall bias. The data are therefore considered to be reasonably reliable.

All São Pedro Health Centre patient records were reviewed for the period of October 2005-October 2006 and all patients visiting the Health Centre during the 30 days prior to the 2007 household survey were interviewed about the reasons for their visits by trained nursing students. This information was gathered to estimate health centre-specific utilisation rates for different health problems, including schistosomiasis and other intestinal infections.

Analytic conceptual framework - A model was developed (Fig. 1) based on relevant accessibility and utilisation studies (Andersen 1995, Travassos et al. 2000, Hendryx et al. 2002, Kumar 2004, Travassos \& Martins 2004, Gerhardt 2006) and was used as a guide in designing this study and assessing the utilisation of primary health care related to schistosomiasis. For this study, we considered all socioeconomic and demographic factors, spatial factors, place of residence and two health services-related factors (cost of diagnosis and of treatment).

Parasitological methods and treatment - During our parasitological survey in July 2007, all study households and members in the study area were examined for schistosomiasis and positive cases were treated. Each person 
TABLE I

Demographic and socioeconomic data and the water supply/sanitation situation in the central village and rural area, São Pedro, Minas Gerais, Brazil, 2007

\begin{tabular}{|c|c|c|c|}
\hline Variables & $\begin{array}{c}\text { Central } \\
\mathrm{n}=935(\%)\end{array}$ & $\begin{array}{c}\text { Rural } \\
\mathrm{n}=293(\%)\end{array}$ & $\mathrm{p}$ value \\
\hline \multicolumn{4}{|l|}{ Gender } \\
\hline Male & $448(47.9)$ & $158(53.9)$ & 0.109 \\
\hline Female & $487(52.1)$ & $135(46.1)$ & - \\
\hline \multicolumn{4}{|l|}{ Age group (years) } \\
\hline $1-14$ & $339(36.4)$ & $77(26.3)$ & $<0.001$ \\
\hline $15-34$ & $268(28.6)$ & $70(23.9)$ & - \\
\hline $35-64$ & $230(24.6)$ & $106(36.2)$ & - \\
\hline$\geq 65$ & $98(10.4)$ & $40(13.6)$ & - \\
\hline \multicolumn{4}{|l|}{ Occupation } \\
\hline Agriculture & $98(10.4)$ & $100(34.1)$ & $<0.001$ \\
\hline Retired & $123(13.2)$ & $42(14.3)$ & - \\
\hline Student or under age & $400(42.8)$ & $89(30.4)$ & - \\
\hline All other & $314(33.6)$ & $62(21.2)$ & - \\
\hline \multicolumn{4}{|l|}{ Education } \\
\hline Illiterate & $127(13.6)$ & $73(24.9)$ & $<0.001$ \\
\hline Under age & $147(15.7)$ & $32(10.9)$ & - \\
\hline $1-8$ years schooling & $581(62.1)$ & $162(55.3)$ & - \\
\hline$\geq 9$ years schooling & $80(8.6)$ & $26(8.9)$ & - \\
\hline \multicolumn{4}{|l|}{ Per capita income in Reais $^{a}$} \\
\hline $0-60$ & $315(33.7)$ & $72(24.6)$ & 0.039 \\
\hline $61-100$ & $232(24.8)$ & $65(22.2)$ & - \\
\hline 101 or higher & $388(41.5)$ & $156(53.2)$ & - \\
\hline Financial support Bolsa Família & 579 (61.9) & $142(48.2)$ & $<0.001$ \\
\hline \multicolumn{4}{|l|}{ Home ownership } \\
\hline Own & $748(80)$ & $215(73.4)$ & $<0.001$ \\
\hline Rent & $42(4.5)$ & 0 & 0 \\
\hline "Rent-free" & $145(15.5)$ & $78(26.6)$ & - \\
\hline \multicolumn{4}{|l|}{ Number of people per room } \\
\hline $0.09-0.80$ & $465(49.7)$ & $198(67.6)$ & $<0.001$ \\
\hline $0.81-1.33$ & $367(39.3)$ & $48(16.4)$ & - \\
\hline $1.34-6$ & $107(11)$ & $47(16)$ & - \\
\hline Own car & $30(3.2)$ & $20(6.8)$ & 0.008 \\
\hline Own bicycle & $443(47.4)$ & $84(28.6)$ & $<0.001$ \\
\hline Own motorcycle & $32(3.4)$ & $23(7.9)$ & $<0.001$ \\
\hline \multicolumn{4}{|l|}{ Quality of house } \\
\hline $\operatorname{Good}^{b}$ & $379(40.3)$ & $157(54.7)$ & 0.391 \\
\hline Poor $^{c}$ & $562(59.7)$ & $130(45.3)$ & - \\
\hline No latrine & $177(18.9)$ & $163(55.6)$ & $<0.001$ \\
\hline Electricity & $758(81.1)$ & $130(44.4)$ & $<0.001$ \\
\hline \multicolumn{4}{|l|}{ Water supply } \\
\hline Piped river water & $752(80.4)$ & 0 & - \\
\hline Stream and other surface waters & $183(19.6)$ & $293(100)$ & $<0.001$ \\
\hline
\end{tabular}

$a$ : about \$US0.50; $b$ : internal and external conditions: house was clean, good quality construction and maintenance of house, floor was ceramic or cement, walls were brick and the roof was tile; $c$ : internal and external conditions: house was dirty, poorly constructed or maintained, floor was dirt, walls were wood or adobe and the roof was asbestos or straw. 


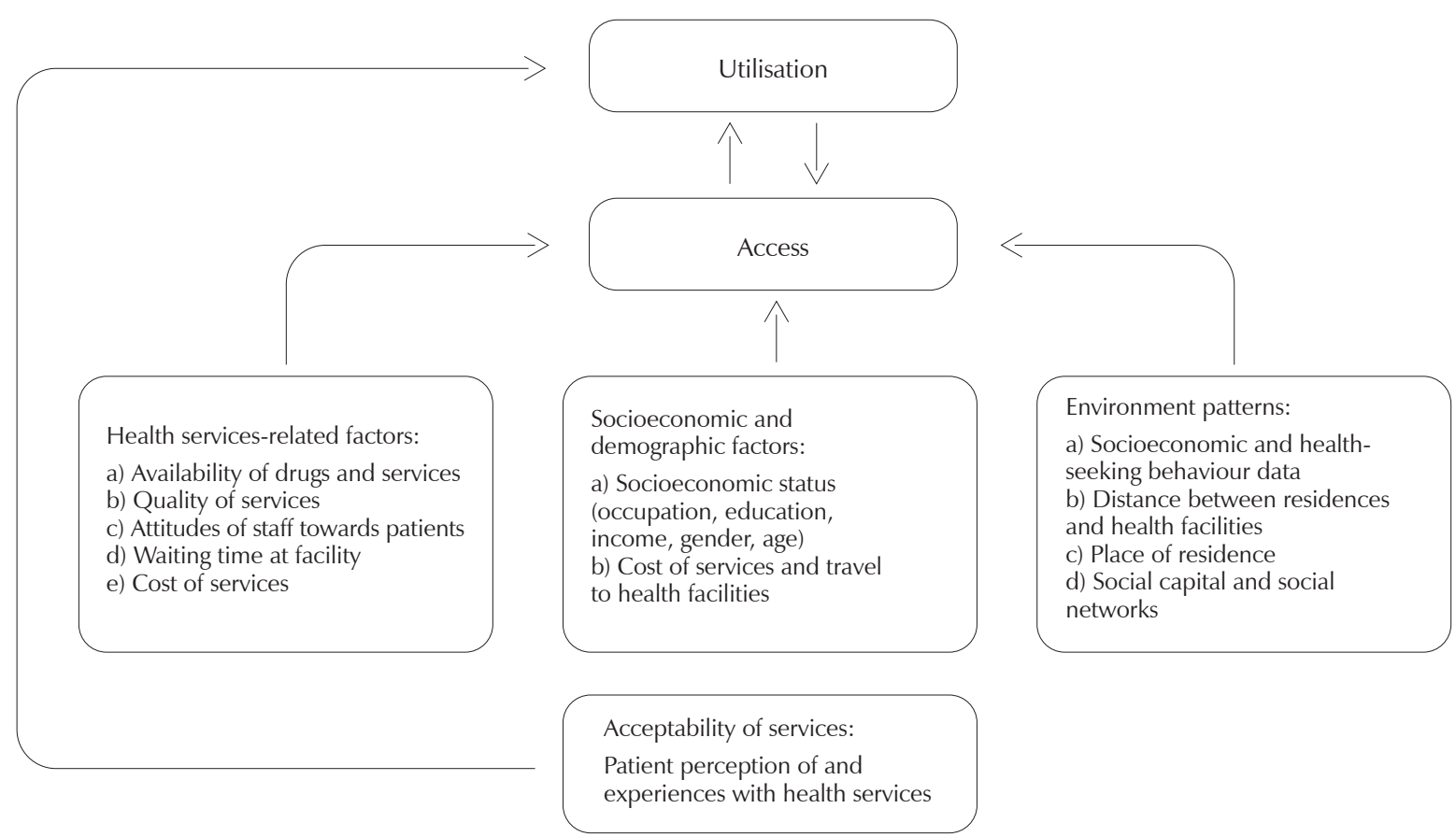

Fig. 1: analytic conceptual framework to assess the utilisation of schistosomiasis-related primary health care.

was given three plastic containers for faecal samples. Individuals in the household who were not included in the study also received containers. Containers were labelled with the participant's full name, age, personal identification number and household identification number. Participants were instructed to deposit one faecal sample per day into each container and return the containers immediately to one of several collection points, where the samples were stored at $4^{\circ} \mathrm{C}$. Faecal samples returned more than $48 \mathrm{~h}$ after container distribution were not accepted and new containers were issued. Slides were prepared within $24 \mathrm{~h}$ of collection using the Kato-Katz thick-smear technique (Katz et al. 1972); two slides were prepared from each day's stool sample, for a total of six slides per individual. Three laboratory technicians carried out the microscopic examination at a field laboratory in the Health Centre in São Pedro. The stool examination extended from July until October 2007 and the treatment of schistosomiasis-infected individuals was administered in January 2008.

Data analysis - All survey data were entered in the field into PDA (Dell Axim X50/GPS System); these devices enabled local data management, analysis and georeferencing of households. The distance between individual houses and the São Pedro Health Centre was measured with the PDA/GPS unit using the straight-line method.

Statistical analysis was performed using SPSS Version 15.0. Descriptive statistics were used to analyse the relationship between the dependent variable (utilisation of health services by schistosomiasis-infected persons) and socioeconomic, demographic and cultural variables during the 2002 schistosomiasis campaign and during the period between 2002-2006. In addition, the study analysed schistosomiasis-related symptoms and actions taken by central villagers and rural area residents during the 30 days before the survey in 2007. A chi-square test was used to test for significance.

Several major accessibility and utilisation parameters were included. First, the survey assessed participation in the 2002 schistosomiasis case-finding campaign. Although this campaign should be carried out every two years according to the recommendations of the federal Ministry of Health, it has not been done in the study area since 2002. All study members were asked if they had a stool test during the health service campaign in 2002 , whether they were positive for schistosomiasis, if they had received treatment and, if not, why not.

Second, the survey examined self-motivated health care for the diagnosis and treatment of schistosomiasis between 2002-2006. Study members were asked if they had had a stool test since the 2002 campaign and, if so, were asked about the testing location, transport and treatment costs, sources of information about and assistance with schistosomiasis treatment (including social networks) and reasons for not treating positive cases. Study participants were then asked whether they had diarrhoea, abdominal pain or blood in the stool (yes/no) during the 30 days preceding the 2007 survey. If they answered yes, the researchers asked what action they had taken.

Third, the study examined crude population-based utilisation rates for schistosomiasis and other health problems based on the São Pedro Health Centre's patient records for a one-year period.

Fourth, the study examined the utilisation of the São Pedro Health Centre for intestinal infections and other major health problems based on patient interviews during a 30-day period. 


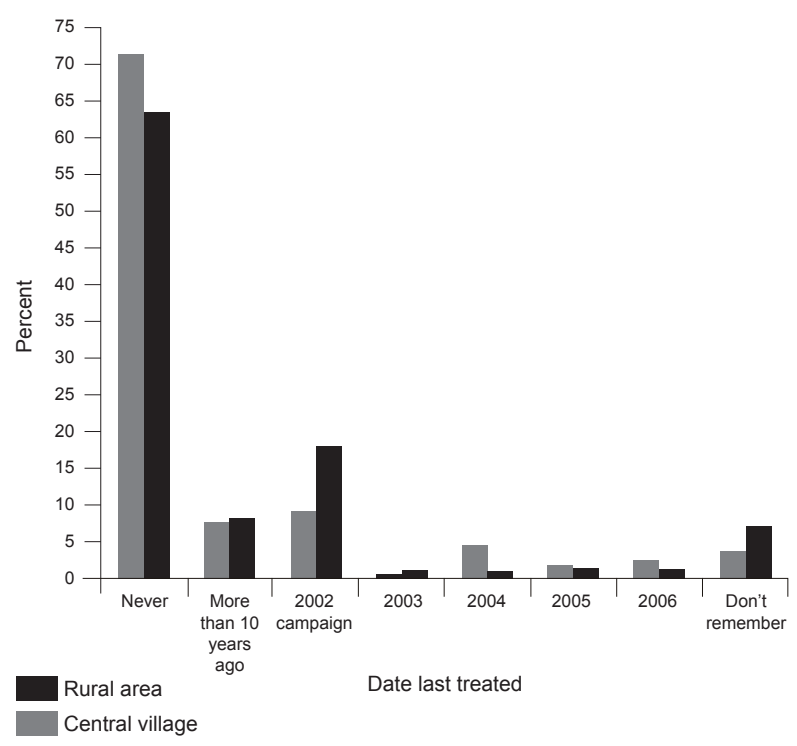

Fig. 2: percentage of study members in the central village $(n=941)$ and the rural area $(n=287)$ who self-reported their last schistosomiasis treatment during each year between 2002-2006, São Pedro, Minas Gerais, Brazil, 2007.

The results of this study may contribute to identifying major barriers to and opportunities to improve the accessibility and utilisation of health services by schistosomiasis patients.

Ethical issues - The study protocol was approved by the Ethical Committee of the Universidade Federal de Minas Gerais and written informed consent was obtained from all participants.

\section{RESULTS}

Socio-demographic characteristics - Of the 1,241 individuals in the 334 study households, 1,228 participated in the study; 13 persons refused to answer the questionnaire. The study population was composed of $606(49.3 \%)$ males and $622(50.7 \%)$ females. Their ages ranged from less than one year to 95 years (mean 30.5, SD 23.2 years). The two extreme age groups, those below 14 years of age and above 65 years, represented $33.9 \%$ and $11.2 \%$ of the population, respectively. The population in the rural section of São Pedro was significantly older than the population in the central village (Table I). The main occupation in the rural area was farming and there were three times as many farmers $(34.1 \%)$ there than in the central village (10.4\%). About eight times as many households in the rural area owned land and cattle than in the village; this finding is due to the predominance of family-owned farms in the former area and of agricultural labourers and non-agricultural workers in the latter. Education levels, number of persons per house and per room and the proportion of households with latrines and electricity were all significantly higher in the central village than in the rural area $(\mathrm{p}<0.001)$. However, household income was significantly higher in the rural area than in the village $(\mathrm{p}<0.039)$, even though more families in the central village received government financial support (Bolsa Familia) $(61.9 \%)$ than in the rural area (48.2\%) (Table I). Streams containing Biomphalaria sp. were a more important source of domestic water in the village than in the rural area, where springs and artesian wells were more common (Table I).

Schistosomiasis prevalence in the study population was $39.4 \%$ in 2007 , with higher rates in the central village $(44.8 \%)$ than in the rural area $(24.8 \%)(p<0.001)$. Mean egg counts were $26.7 / \mathrm{gm}$ of stool in samples from the central village and $26.3 / \mathrm{gm}$ of stool in samples of the rural area. Most study participants reportedly received their last treatment for schistosomiasis during the 2002 schistosomiasis campaign (Fig. 2).

\section{Access to and utilisation of primary health services: temporal and spatial patterns}

The 2002 schistosomiasis campaign of active case finding - During the Fundação Nacional de Saúde (FUNASA) campaign in $2002,68.3 \%$ of the residents in the central village and $48.7 \%$ of those in the rural area reportedly had a stool test for $S$. mansoni infection $(\mathrm{p}<$ $0.001) ; 33.1 \%$ of the tests from the central village were positive and $26.5 \%$ of the tests from the rural area were positive ( $p<0.001$ ). Rates of treatment were $90.4 \%$ among central village residents and $77.1 \%$ among rural area residents. The main reason positive individuals did not obtain treatment was user-related. They reported fear of side effects and of taking praziquantel simultaneously with other medications for chronic diseases. Nevertheless, more people in the older rural population $(89.3 \%)$ than in the younger central village population $(84 \%)$ reported satisfaction with the campaign. The principal reason for dissatisfaction in both study areas was a lack of information about stool test results; health personnel returned for the purpose of providing treatment only to those houses where there were schistosomiasis-positive individuals and other households did not receive any information about the stool test results (Table II).

Self-motivated health-seeking behaviour between 2002-2006 - The mean straight-line distance between all houses in the study area and the primary Health Centre in São Pedro was $1.93 \mathrm{~km}$ (SD 3.37) and the maximum distance was $14.07 \mathrm{~km}$. Mean distances were $0.38 \mathrm{~km}$ (SD 0.69) in the central village and $7.02 \mathrm{~km}$ (SD 3.64) in the rural area. The rate of self-motivated searches for schistosomiasis-related health care between 2002-2006 was higher among rural residents $(27 \%)$ than central village residents $(23.7 \%)$, but this difference was not statistically significant. While $15.2 \%$ and $16.2 \%$ of rural and central village residents, respectively, were positive for schistosomiasis, only $23.4 \%$ of rural residents and $16.5 \%$ of village residents obtained stool tests at the São Pedro Health Centre. Thus, nearly $39 \%$ and $47 \%$ of the patients in the central village paid for transportation to other health care facilities for diagnostic and treatment services. Questions about the use of social networks in the health-seeking process revealed that $17.1 \%$ of the infected persons in the central village and $10.1 \%$ in the rural area had received help from others; most received information about health services and financial support for travel and hotel costs during the trips for diagnosis and treatment. Although relatively more infected people 
TABLE II

Distribution of schistosomiasis diagnosis and treatment during the Schistosomiasis Control Program in 2002 in central and rural São Pedro, Minas Gerais, Brazil

\begin{tabular}{|c|c|c|c|}
\hline Variables & $\begin{array}{c}\text { Central } \\
\mathrm{n}^{a}=788(\%)\end{array}$ & $\begin{array}{c}\text { Rural } \\
\mathrm{n}^{a}=271(\%)\end{array}$ & $\mathrm{p}$ value \\
\hline Stool test (yes) & $538(68.3)$ & $132(48.7)$ & $<0.001$ \\
\hline Schistosomiasis-positive (yes) & $178(33.1)$ & $35(26.5)$ & $<0.001$ \\
\hline \multicolumn{4}{|l|}{ Received treatment } \\
\hline Yes & $161(90.4)$ & $27(77.1)$ & $<0.001$ \\
\hline No & $17(9.6)$ & $8(22.9)$ & - \\
\hline \multicolumn{4}{|l|}{ Reason for no treatment } \\
\hline Fear of side effects & $4(20)$ & $1(12.5)$ & - \\
\hline Refused treatment or not at home & $3(15)$ & $4(50)$ & - \\
\hline Pregnant/breastfeeding & $3(15)$ & $2(25)$ & - \\
\hline Used medicine or was sick & $6(30)$ & $1(12.5)$ & - \\
\hline Others & $4(20)$ & 0 & - \\
\hline \multicolumn{4}{|l|}{ Satisfaction with health services } \\
\hline Yes & $451(84)$ & $118(89.3)$ & $<0.001$ \\
\hline No & $87(16)$ & $14(10.7)$ & - \\
\hline \multicolumn{4}{|l|}{ Reason for not being satisfied } \\
\hline Did not receive treatment & $6(6.2)$ & $7(46.7)$ & - \\
\hline Did not receive results of stool test & $75(78.1)$ & $8(53.3)$ & - \\
\hline Others & $18(6.2)$ & 0 & - \\
\hline
\end{tabular}

$a$ : number of study participants who lived in these areas in 2002 .

in the central village received such help, slightly larger proportions of people in the rural area obtained both stool examinations and treatment (Table III).

Utilisation of the São Pedro Health Centre between 2005-2006 - According to the outpatient records of the São Pedro Health Centre, about 15\% (n = 179) of the study population sought health services between 20052006 for the diagnosis and treatment of intestinal parasitic infections. Physicians and nurses ordered stool tests for $60.3 \%$ of the 108 patients recorded during that oneyear period. Only $28.7 \%$ of patients obtained a stool test and returned to the São Pedro Health Centre for physician evaluation and treatment; $19.7 \%$ were positive for S. mansoni. The physician prescribed albendazole to all patients returning without stool test results (Table IV).

Patient demands for health services in the São Pedro Health Centre during one week in April 2008 were also studied. This study revealed that most users arrived for the testing or treatment of hypertension $(28.5 \%)$, dental problems $(16.5 \%)$, respiratory infection $(14.5 \%)$ and intestinal infections, including schistosomiasis (10.5\%).

The 2007 survey about symptoms and actions taken - Symptoms perceived to be schistosomiasis-related during the 30 days preceding the 2007 survey were reported by $15.4 \%$ of the respondents in the central village and by $18.1 \%$ of those in the rural area. Specifically, $57.2 \%$ reported diarrhoea, $27.7 \%$ reported stool blood and $12.8 \%$ reported abdominal pain. However, only $11.8 \%$ of the infected people sought care for those symptoms at a health facility and most people in both

\section{TABLE IV}

Utilization of São Pedro Health Center for a 12 month period, 2005-2006, for diagnostic and treatment of intestinal parasitic infections among the study participants, based on patient records

\begin{tabular}{lc}
\hline Variables & $\mathrm{n}=1,228(\%)$ \\
\hline Patients presenting with symptoms & $179(14.6)$ \\
Stool tests ordered by the physician/or nurse & $108(60.3)$ \\
Patients obtaining stool test & $31(28.7)$ \\
Schistosomiasis-positive tests & $6(19.7)$ \\
Patients who received treatment & $60(5.6)$ \\
Albendazole & $56(81.1)$ \\
Metronidazole & $5(7.2)$ \\
Praziquantel & $4(5.7)$ \\
Other worm medications & $4(5.7)$ \\
\hline
\end{tabular}

areas used traditional medicines. In the central village, more study members participated in community groups than in the rural area $(p<0.001)$ and used home remedies (medicinal plants) to treat diarrhoea, blood in the stool and abdominal pain (Table V).

\section{DISCUSSION}

The major finding of this study is the large discrepancy between the relatively high coverage of the population with diagnostic and treatment services during the 


\section{TABLE III}

Utilization of schistosomiasis-related health services reported by residents of central and rural São Pedro between 2003-2006, Minas Gerais, Brazil

\begin{tabular}{|c|c|c|c|}
\hline Variables & $\begin{array}{c}\text { Central } \\
\mathrm{n}=935(\%)\end{array}$ & $\begin{array}{c}\text { Rural } \\
\mathrm{n}=293(\%)\end{array}$ & $\mathrm{p}$ value \\
\hline Stool test (yes) & $222(23.7)$ & $79(27)$ & 0.297 \\
\hline \multicolumn{4}{|l|}{ Place of stool test } \\
\hline Local health center & $37(16.5)$ & $18(23.4)$ & 0.007 \\
\hline Regional health center and health center in another town & $185(83.5)$ & $61(76.6)$ & - \\
\hline \multicolumn{4}{|l|}{ Patients paying for travel and/or diagnosis ${ }^{a}(\mathrm{n})$} \\
\hline Transport & $86(38.7)$ & $26(32.9)$ & - \\
\hline Private doctor & $26(11.7)$ & $19(24.1)$ & 0.053 \\
\hline Laboratory & $44(19.8)$ & $20(25.3)$ & - \\
\hline No expenses involved & $66(29.7)$ & $14(17.7)$ & - \\
\hline Schistosomiasis-positive & $36(16.2)$ & $12(15.2)$ & 1.0 \\
\hline Received treatment & $32(88.9)$ & $11(91.7)$ & 1.0 \\
\hline \multicolumn{4}{|l|}{ Place of treatment } \\
\hline São Pedro Health Center & $6(18.7)$ & $1(9)$ & - \\
\hline Health facilities in other communities & $26(81.3)$ & $10(91)$ & - \\
\hline Patients not receiving treatment ${ }^{b}$ & $4(100)$ & $1(100)$ & - \\
\hline Satisfied with health services (yes) & $214(96.4)$ & $79(100)$ & 0.210 \\
\hline \multicolumn{4}{|l|}{ Patients paying for transport and/or treatment (n) } \\
\hline Medication & $8(25)$ & $2(18.2)$ & - \\
\hline Transport & $15(46.9)$ & $1(9.1)$ & - \\
\hline Private doctor & $1(3.1)$ & 0 & - \\
\hline No expenses involved & $8(25.0)$ & $8(72.7)$ & - \\
\hline \multicolumn{4}{|l|}{ Type of help received in health-seeking } \\
\hline Identifying health services & $1(0.5)$ & $2(2.5)$ & - \\
\hline Guest house/hotel costs & $24(10.8)$ & $5(6.3)$ & - \\
\hline Transport costs & $12(5.4)$ & $1(1.3)$ & - \\
\hline Treatment costs & $1(0.5)$ & 0 & - \\
\hline No help received & $184(82.9)$ & $71(89.9)$ & - \\
\hline
\end{tabular}

$a$ : mean cost of a stool test was \$US5.62 and mean cost of treatment was \$US47.56; $b$ : three of the patients in the central village lacked money and one patient each in the central village and in the rural area could not obtain drugs.

2002 schistosomiasis campaign and the small proportion of the population that reported receiving its last treatment during the 2002-2006 period (24.5\%). This difference appears to be due to a combination of factors, including the non-specific symptoms of most $S$. mansoni infections (which leave many people unaware of their infection) and the two access parameters of availability and affordability of health services. These constraints have also been reported by other investigators (Uchôa et al. 2000, Thiede \& McIntyre 2008). The temporal patterns that were recorded provide a crude measure of the need for schistosomiasis health services in the absence of the FUNASA campaign in São Pedro, even though the recalled data covering a 5-year period are subject to underreporting. The lower coverage of rural households by the 2002 campaign's stool survey appears to be due to the relative inaccessibility of the area outside São Pedro by automobile, which hindered health agents from reaching some households. The higher rates of partici- pation of people in the central village indicate that the strategy of periodic campaigns works in rural areas with limited access to laboratory and treatment facilities.

The low utilisation rates reported for the 30-day period prior to the 2007 survey appear to be due to people's anticipation of project treatment. These data were therefore not used in the analysis. The unusually high rate (above 90\%) of home remedies used during that 30-day period also suggests that infected people waited for project treatment. Although significantly more people received schistosomiasis-related services during the 2002 campaign than during the subsequent four years when infected persons were required to access services by themselves, the fact that only half of the study population in the rural area and less than two-thirds of those in the central village were examined during that campaign indicates program shortcomings. Additional studies in other communities may reveal these and other program shortcomings and constraints that must be overcome as 
TABLE V

Laboratory-diagnosed Schistosoma mansoni infections, schistosomiasis-related symptoms experienced during one month prior to the survey in 2007 and actions taken by study members in central and rural São Pedro, Minas Gerais, Brazil

\begin{tabular}{lccc}
\hline Variables & $\begin{array}{c}\text { Central } \\
\mathrm{n}=935(\%)\end{array}$ & $\begin{array}{c}\text { Rural } \\
\mathrm{n}=293(\%)\end{array}$ & $\mathrm{p}$ value \\
\hline $\begin{array}{l}\text { Schistosomiasis-related symptoms (yes) } \\
\text { Type of symptoms }\end{array}$ & $144(15.4)$ & $53(18.1)$ & 0.201 \\
$\quad$ Diarrhoea & $110(57.2)$ & $42(65.6)$ & 0.185 \\
$\quad$ Blood in stool & $56(29.1)$ & $15(23.4)$ & 0.645 \\
$\quad$ Abdominal pain & $26(13.7)$ & $7(11)$ & 0.766 \\
Actions taken & & 0 & - \\
$\quad$ Went to local health centre & $17(11.8)$ & $1(1.9)$ & - \\
$\quad$ Went to regional hospital & $11(7.6)$ & $46(86.8)$ & - \\
$\quad$ Used home remedies & $92(63.9)$ & $6(11.3)$ & - \\
Did nothing & $24(16.7)$ & & \\
\hline
\end{tabular}

part of the move from the control phase to the maintenance phase of the Brazilian SCP (WHO 2001).

The temporal pattern of diagnosis and treatmentseeking behaviour for schistosomiasis in São Pedro between 2002-2007 shows low utilisation rates of the health services (Tables III-V). These low rates may be due to the common lay perception that schistosomiasis and other intestinal infections are relatively benign and do not require medical treatment and to a lack of knowledge about the prevention and transmission of schistosomiasis (Danso-Appiah et al. 2004, Freudenthal et al. 2006, Gazzinelli et al. 2006c) and to the high cost of accessing health services (Table III) (Yu et al. 2001).

This study of health services accessibility and utilisation at the community level reveals significant differences within the small rural area of São Pedro. A greater need for schistosomiasis services existed in the central village, where schistosomiasis was more prevalent than in the surrounding rural area because of a greater exposure risk and a younger and poorer population. The greater need for treatment and support in the central village is also reflected in the greater reliance on social networks for information and financial support for obtaining health services than in the rural area. Similar inequities in care-seeking behaviour were reported by Schellenberg et al. (2003) among poor children in a rural area in Tanzania.

The reasonably high population coverage of the 2002 case-finding campaign (Table II) and the low rates of self-motivated health care utilisation during the subsequent 2002-2006 period (Table IV) argue for the continuation of the vertical program currently being used by Brazil's SCP and further integration into the primary health services in all endemic areas, especially in rural areas lacking treatment and laboratory facilities. This will also require the development of community-based health education programs to improve population perceptions and knowledge of the signs and symptoms of schistosomiasis as well as the availability of effective antischistosomal drugs. This education may encourage individuals to initiate the health care seeking process early and promote preventive behaviour. Improved access to health services, proper and timely treatment, effective patient strategies and the availability of praziquantel have been shown to be effective interventions (Favre et al. 2001, Van der Werf et al. 2002, Danso-Appiah et al. 2004, de Vlas et al. 2004, Liu et al. 2005, Raso et al. 2005).

The relatively low utilisation of schistosomiasis services by children and the poorest segments of the population of São Pedro, combined with their relatively high infection rates, points to the importance of continuing the biannual schistosomiasis case-finding campaigns and accelerating the integration of schistosomiasis control activities into the primary health services. This study also indicates that a school-based diagnostic and treatment program in São Pedro may increase coverage of highly infected children. From a methodological perspective, long-term retrospective data could provide complementary longitudinal information on the accessibility and utilisation of primary health services in São Pedro. Similar studies might be used in other poor rural areas lacking adequate health records.

There is a need for population-based health services utilisation studies in other endemic areas; both health service records and survey methods can be used to examine population coverage and impediments to healthseeking behaviour. This study also indicates that small rural communities in Brazil are not homogeneous; socioeconomic, demographic and spatial/environmental differences all affect the accessibility and utilisation of schistosomiasis services. In addition, the organisation and operation of primary health services need to be examined within the socio-political context of local health service provisions and administrative organisations. This examination may help improve the efficient control of schistosomiasis and other parasites in the recently decentralised health system. 


\section{REFERENCES}

Almeida C, Travassos C, Porto S, Labra ME 2000. Health sector reform in Brazil: a case study of inequity. Int J Health Serv 30: 129-162.

Andersen RM 1995. Revisiting the behavioral model and access to medical care: does it matter? J Health Soc Behav 36: 1-10.

Andersen RM, Yu H, Wyn R, Davidson PL, Brown ER, Teleki S 2002. Access to medical care for low-income persons: how do communities make a difference? Med Care Res Rev 59: 384-411.

Assis MM, Villa TC, Nascimento MA 2003. Acesso aos serviços de saúde: uma possibilidade a ser construída na prática. Cien Saude Colet 8: 815-823.

Barata RB, de Almeida MF, Montero CV, da Silva ZP 2007. Health inequalities based on ethnicity in individuals aged 15 to 64, Brazil, 1998. Cad Saude Publica 23: 305-313.

Barbosa CS, Araújo KC, Antunes L, Favre T, Pieri OS 2004. Spatial distribution of schistosomiasis foci on Itamaracá Island, Pernambuco, Brazil. Mem Inst Oswaldo Cruz 99 (Suppl. I): 79-83.

Barbosa CS, Favre TC, Wanderley TN, Callou AC, Pieri OS 2006. Assessment of schistosomiasis, through school surveys, in the Forest Zone of Pernambuco, Brazil. Mem Inst Oswaldo Cruz 101 (Suppl. I): 55-62.

Barbosa FS 1995. Determination and control of schistosomiasis. Mem Inst Oswaldo Cruz 90: 155-159.

Bethony J, Williams JT, Kloos H, Blangero J, Alves-Fraga L, Buck G, Michalek A, Williams-Blangero S, LoVerde PT, Corrêa-Oliveira R, Gazzinelli A 2001. Exposure to Schistosoma mansoni infection in a rural area in Brazil. II. Household risk factors. Trop Med Int Health 6: 136-145.

Coura JR 1995. Control of schistosomiasis in Brazil: perspectives and proposals. Mem Inst Oswaldo Cruz 90: 257-260.

Coura JR, Amaral RS 2004. Epidemiological and control aspects of schistosomiasis in Brazilian endemic areas. Mem Inst Oswaldo Cruz 99 (Suppl. I): 13-19.

da Silva NN, Pedroso GC, Puccini RF, Furlani WJ 2000. Desigualdades sociais e uso de serviços de saúde: evidências de análise estratificada. Rev Saude Publica 34: 44-49.

Danso-Appiah A, de Vlas SJ, Bosompem KM, Habbema JD 2004. Determinants of health-seeking behaviour for schistosomiasisrelated symptoms in the context of integrating schistosomiasis control within the regular health services in Ghana. Trop Med Int Health 9: 784-794.

de Vlas SJ, Danso-Appiah A, van der Werf MJ, Bosompem KM, Habbema JD 2004. Quantitative evaluation of integrated schistosomiasis control: the example of passive case finding in Ghana. Trop Med Int Health 9: A16-A21.

Engels D, Chitsulo L, Montresor A, Savioli L 2002. The global epidemiological situation of schistosomiasis and new approaches to control and research. Acta Trop 82: 139-146.

Enk MJ, Caldeira RL, Carvalho OS, Schall VT 2004. Rural tourism as risk factor for the transmission of schistosomiasis in Minas Gerais, Brazil. Mem Inst Oswaldo Cruz 99 (Suppl. I): 105-108.

Favre TC, Pieri OS, Barbosa CS, Beck L 2001. Evaluation of control measures implemented from 1977 to 1996 in the endemic area of schistosomiasis in Pernambuco, Brazil. Rev Soc Bras Med Trop 34: 569-576.

Favre TC, Ximenes RA, Galvão AF, Pereira AP, Wandereley TN, Barbosa CS, Pieri OS 2006. Attaining the minimum target of resolution WHA 54.19 for schistosomiasis control in the Rainforest Zone of the state of Pernamubuco, Northeastern Brazil. Mem Inst Oswaldo Cruz 101 (Suppl. I): 125-132.
Freudenthal S, Ahlberg BM, Mtweve S, Nyindo P, Poggensee G, Krantz I 2006. School-based prevention of schistosomiasis: initiating a participatory action research project in Northern Tanzania. Acta Trop 100: 79-87.

FUNASA - Fundação Nacional da Saúde 1998. Controle da esquistossomose: diretrizes técnicas, Ministério da Saúde, Brasília, 70 pp.

Gazzinelli A, Gazzinelli MF, Cadete MM, Pena Filho S, Sá IR, Kloos H 1998. Sociocultural aspects of schistosomiasis mansoni in an endemic area in Minas Gerais, Brazil. Cad Saude Publica 14: 841-849.

Gazzinelli A, Hightower A, LoVerde PT, Haddad JP, Pereira WR, Bethony J, Correa-Oliveira R, Kloos H 2006a. The spatial distribution of Schistosoma mansoni infection before and after chemotherapy in the Jequitinhonha Valley in Brazil. Mem Inst Oswaldo Cruz 101 (Suppl. I): 63-71.

Gazzinelli A, Velásquez-Melendez G, Crawford SB, LoVerde PT, CorreaOliveira R, Kloos H 2006b. Socioeconomic determinants of schistosomiasis in a poor rural area in Brazil. Acta Trop 99: 260-271.

Gazzinelli MF, Reis DC, Kloos H, Velásquez-Melendez G, Dutra IR, Gazzinelli A 2006c. The impact of two education methods on knowledge of schistosomiasis transmission and prevention among schoolchildren in a rural community in northern Minas Gerais, Brazil. Mem Inst Oswaldo Cruz 101 (Suppl. I): 45-53.

Gerhardt TE 2006. Itinerários terapêuticos em situações de pobreza: diversidade e pluralidade. Cad Saude Publica 22: 2449-2463.

Gesler WM 1984. Health care in developing countries, Association of American Geographers, Washington, 88 pp.

Guimarães RJ, Freitas CC, Dutra LV, Moura AC, Amaral RS, Drummond SC, Guerra M, Scholte RG, Freitas CR, Carvalho OS 2006. Analysis and estimative of schistosomiasis prevalence for the state of Minas Gerais, Brazil, using multiple regression with social and environmental spatial data. Mem Inst Oswaldo Cruz 101 (Suppl. I): 91-96.

Haile-Mariam D, Kloos H 2006. Modern health services. In Y Berhane, D Haile Mariam, H Kloos (eds.), The epidemiology and ecology of health and disease in Ethiopia, Shama Books, Addis Ababa, p. 226-255.

Hendryx MS, Ahern MM, Lovrich NP, McCurdy AH 2002. Access to health care and community social capital. Health Serv Res 37: 87-103.

Jurberg C 2008. Flawed but fair: Brazil's health system reaches out to the poor. Bull World Health Organ 86: 248-249.

Katz N 1998. Schistosomiasis control in Brazil. Mem Inst Oswaldo Cruz 93 (Suppl. I): 33-35.

Katz N, Chaves A, Pellegrino J 1972. A simple device for quantitative stool thick-smear technique in schistosomiasis mansoni. Rev Inst Med Trop Sao Paulo 14: 397-400.

Kloos H, Gazzinelli A, Zuyle PV 1998. Microgeographical patterns of schistosomiasis and water contact behavior; examples from Africa and Brazil. Mem Inst Oswaldo Cruz 93 (Suppl. I): 37-50.

Kumar N 2004. Changing geographic access to and locational efficiency of health services in two Indian districts between 1981 and 1996. Soc Sci Med 58: 2045-2067.

Lee SY, Arozullah AM, Cho YI 2004. Health literacy, social support and health: a research agenda. Soc Sci Med 58: 1309-1321.

Lima e Costa MF, Rocha RS, Firmo JO, Guerra HL, Passos VA, Katz N 1998. Questionnaires in the screening for Schistosoma mansoni infection: a study of socio-demographic and water contact variables in four communities in Brazil. Rev Inst Med Trop Sao Paulo 40: 93-99. 
Liu ZC, Xiao SY, Yu DB, Li YS, Fang JC, Li HZ, Zhang JH 2005. In-depth interviews on late stage schistosomiasis patients about factors related to prevention and treatment in the rural areas. Zhonghua Liu Xing Bing Xue Za Zhi 26: 14-17.

Mendoza-Sassi R, Béria JU, Barros AJD 2003. Fatores associados à utilização de serviços ambulatoriais: estudo de base populacional. Rev Saude Publica 37: 372-378.

MS - Ministério da Saúde Brasil 2005. Guia de vigilância epidemiológica, 6th ed., Ministério da Saúde, Brasília, 816 pp.

MS - Ministério da Saúde Brasil 2008. Vigilância e controle de moluscos de importância epidemiológica. Diretrizes técnicas: programa de vigilância e controle da esquistossomose (PCE), 2nd ed., Ministério da Saúde, Brasília, 177 pp.

Raso G, Utzinger J, Silué KD, Ouattara M, Yapi A, Toty A, Matthys B, Vounatsou P, Tanner M, N'Goran EK 2005. Disparities in parasitic infections, perceived ill health and access to health care among poorer and less poor schoolchildren of rural Côte d'Ivoire. Trop Med Int Health 10: 42-57.

Sastry N 1997. What explains rural-urban differentials in child mortality in Brazil? Soc Sci Med 44: 989-1002.

Savioli L, Albonico M, Engels D, Montresor A 2004. Progress in the prevention and control of schistosomiasis and soil-transmitted helminthiasis. Parasitol Int 53: 103-113.

Schellenberg JA, Victoria CG, Mushi A, de Savigny D, Schellenberg D, Mshinda H, Bryce J, Tanzania Integrated Management of Childhood Illness MCE Baseline Household Survey Study Group 2003. Inequities among the very poor: health care for children in rural Southern Tanzania. Lancet 361: 561-566.

Silva RC, Barreto ML, Assis AM, de Santana ML, Reis MG, Parraga IM, Blanton RE 2007. The relative influence of polyparasitism, environment and host factors on schistosome infection. Am $J$ Trop Med Hyg 4: 672-675.
Thiede M, McIntyre D 2008. Information, communication and equitable access to health care: a conceptual note. Cad Saude Publica 24: $1168-1173$.

Travassos C, Martins M 2004. Uma revisão sobre os conceitos de acesso e utilização de serviços de saúde. Cad Saude Publica 20 (Suppl. 2): S190-S198.

Travassos C, Viacava F, Fernandes C, Almeida CM 2000. Desigualdades geográficas e sociais na utilização de serviços de saúde no Brasil. Cien Saude Colet 5: 133-149.

Uchôa E, Barreto SM, Firmo JO, Guerra HL, Pimenta FG Jr, Lima e Costa MF 2000. The control of schistosomiasis in Brazil: an ethnoepidemiological study of the effectiveness of a community mobilization program for health education. Soc Sci Med 51: $1529-1541$

Van der Werf MJ, de Vlas SJ, Looman CW, Nagelkerke NJ, Habbema JD, Engels D 2002. Associating community prevalence of Schistosoma mansoni infection with prevalence of signs and symptoms. Acta Trop 82: 127-137.

Watts S 2008. The social determinants of schistosomiasis. Working paper prepared for the Scientific Working Group meeting on Schistosomiasis Research, Special Programme for Research and Training in Tropical Diseases, Geneva, 14-16 November 2005. Available from: http://www.tropika.net/review/051114-Schistosomiasis_Social_Determinants/article.pdf .

WHO - World Health Organization 2001. Report of the WHO informal consultation on schistosomiasis in low transmission areas: control strategies and criteria for elimination, London, WHO report $\mathrm{WHO} / \mathrm{CDS} / \mathrm{CPE} / \mathrm{SIP} / 2001.1$.

Yu D, Manderson L, Yuan L, Wei W, He H, Chen Y 2001. Is equity being sacrificed? Willingness and ability to pay for schistosomiasis control in China. Health Policy Plan 16: 292-301. 